\title{
SEM-EDX Analysis for Surface Aberrations of Neonate's Teeth Influenced by the use of Lithium in Pregnancy
}

\author{
${ }^{1}$ Shakila Nazir, ${ }^{2}$ Naeem H Naqvi, ${ }^{3}$ Masood A, ${ }^{4}$ Naema N \\ ${ }^{1}$ Professor, Department of Oral Biology, Baqai Dental College and Baqai Medical University, Karachi, Pakistan \\ ${ }^{2}$ Professor, Department of Pharmacology, Baqai Institute of Pharmaceutical Sciences, Baqai Medical University, Karachi, Pakistan \\ ${ }^{3}$ Professor, Department of Anatomy, Baqai Medical University, Karachi, Pakistan \\ ${ }^{4}$ Postgraduate Trainee, Abbasi Shaheed Hospital, Karachi, Pakistan
}

Correspondence: Shakila Nazir, Professor, Department of Oral Biology, Baqai Dental College and Baqai Medical University Karachi, Pakistan, Phone: 03008283345, e-mail: shakila.nazir@gmail.com

\begin{abstract}
Objective of the study: Developmental defects of enamel may lead to esthetic tribulations. Malformed dental enamel is usually susceptible to caries and sensitivity of teeth. The objective of the present study was to evaluate the distribution of developmental defects affecting the enamel surfaces in the teeth of newborn babies of the mothers, caused by the use of lithium for a long time during pregnancy.

Study design/methods: The female rabbits were kept on this drug during pregnancy and their offsprings were used for the study. They were sacrificed to obtain their jaws. Teeth were extracted for assessment of the congenital defects developed during intrauterine life. Surface structure was studied by scanning electron microscopy and energy-dispersive X-ray microanalysis (SEM-EDX).

Results: The results showed that the drug had caused erosions of the incisors and the molars, as compared to the premolars.

Conclusion: According to the results, incisors and the molars appeared esthetically and functionally compromised teeth. The drug should, therefore, be used by doctor's prescription only, especially during pregnancy, avoiding the teratogenic effect on the dentition of the newborns.

Keywords: Lithium, Developmental teratogenicity, Female rabbits, Dentition.
\end{abstract}

\section{INTRODUCTION}

Lithium carbonate is often referred to as an antimanic drug, but in many parts of the world it is considered as a 'moodstabilizing' agent because of its primary action of preventing mood swings in patients with bipolar affective (manicdepressive) disorder. ${ }^{1}$ O ral and dental structures are frequently the sites of adverse drug reactions. These include salivary glands, oral mucosa, periodontal tissues, teeth, alveolar bone and other structures. ${ }^{2}$ The 'mood-stabilizing' agents are commonly used in pregnancy which could possibly cause teratogenic effects in any of the developing body tissue.

Lithium is absorbed completely from gastrointestinal tract within 8 hours, initially distributed in extracellular fluid and then gradually accumulates in various tissues and transferred to fetus through placenta. ${ }^{1} \mathrm{H}$ ow ever, more recent data suggests that lithium carries a relatively low risk of teratogenic effects. ${ }^{3}$ A meloblasts and odontoblasts are responsible for the formation of two important dental tissues, i.e. enamel and dentine respectively. These cells are very sensitive to the teratogenic stimuli, febrile diseases and any drug used by the pregnant female. Gross anatomical malformations result from disturbed morphogenesis, from 18 to 55 days of intrauterine life, which is the most susceptible period for adverse drug effects. A single dysmorphogenic agent interferes with the simultaneous organization of many systems and may produce a multiplicity of malformation at various sites. ${ }^{4}$

M ore than $90 \%$ of pregnant women take prescription or nonprescription (over-the-counter) drugs during pregnancy, which can act directly on the fetus, may cause damage, leading to birth defects or death reported in "The Merck M anual" (2007). ${ }^{5}$ Prior investigations revealed that drug can produce untoward consequences, even when used according to standard or recommended methods of administration. Furthermore adverse drug reactions can involve every organ and system of the body, so mouth and associated structures may also be affected by drugs or chemicals. ${ }^{6}$ Regarding the deciduous dentition, the developmental defects of enamel was observed in the second molars $(44.4 \%)$, being the most affected teeth followed by the first molars $(23.5 \%)$. D efects in the teeth of upper arch were more $(58.2 \%)$ reported by Lunardelli and Peres (2005). Prevalence of enamel hypoplasia, in the canines was $33.6 \%$ and second molars 33.6\%. ${ }^{7}$ D emarcated opacities reported by A rrow (2008), affected $(11 \%)$ on the upper right (14\%), upper left $(10 \%)$, lower left and $(9 \%)$ lower right molars. ${ }^{8}$ Whereas according to Thomas (2009), the risk of major congenital malformation in the offspring did not have any significant association to family history. ${ }^{9}$

$M$ ajor body structures are formed in about the first 12 weeks of intrauterine life. Studies revealed that interference in this 
process may cause a teratogenic effect. It was also reported that, if a drug is given after this period, it will not produce a major anatomical defect. Further, the drug is not always teratogenic and harm the fetus in the first trimester. ${ }^{10}$ It was concluded in a prior study that a fine balance for drug administration should be maintained for protecting the baby as well as the mother. ${ }^{11}$

It is quite interesting to know that the lithium is present in traces throughout earth's crust. It is amazingly versatile and can run laptop computers, treat bipolar disorder (though scientists do not know exactly how it prevents mood swings) and even give ceramics a brighter glaze. ${ }^{12}$

\section{MATERIALS AND METHODS}

Rabbits were used as an animal model for this study. Normal healthy female rabbits of 1.5 to $2.0 \mathrm{~kg}$ were selected for the study. They were grouped into two. First group was selected for experimental purpose and the second one was taken as control. There were seven rabbits in each group $(n=7)$.

The drug used was lithium carbonate with the trade name (Neurolith ${ }^{\circledR}$ SR $400 \mathrm{mg}$ ). ${ }^{13}$ Dose of the drug was determined according to the body weight of the animal, calculated and based upon the Clark's rule. ${ }^{14}$

Neurolith ${ }^{\circledR} \mathrm{SR} 400 \mathrm{mg}$ (one tablet) was dissolved in $10 \mathrm{ml}$ of the distilled water to prepare the drug; $3 \mathrm{ml}(80 \mathrm{mg} / \mathrm{kg}$ ) of the preparation was administered orally, twice a week to the female rabbits of the experimental group.

Identification of the animals was done by wrapping the metallic wire around the hind leg of the subjects forming a loop.

The control group consisted of rabbits which were untreated and thus did not require long-term identification, like the study group. They were kept in their individual locations.

Each group consisted of seven rabbits $(n=7)$. Subjects in the control group were designated by, $\mathrm{N}-1, \mathrm{~N}-2, \mathrm{~N}-3, \mathrm{~N}-4$, $\mathrm{N}-5, \mathrm{~N}-6$ and $\mathrm{N}-7$.

The group treated with lithium was identified as $Y 2-5$, Y 6-1, Y 6-2, Y 7-1, Y 7-2, Y 8-1 and Y 8-2.

To distinguish the subjects within each treated group, the colored beads were strung in the colored wires. The number of beads in the wire corresponded to the ordinal number of the rabbit in its group, e.g. in the identity (Y 2-5), "Y 2" indicated the treated group and " 5 " indicated the number of animal used in that particular group. A II the drug-treated female rabbits were kept with equal number of their male partners separately. The drug was administered according to the predetermined dose, until the birth of their offsprings.

A proforma was designed to keep the record of the number of doses administered and for any toxicity developed by the drug, i.e. diarrhea, ulceration, loss of physical activity, loss of interest in food, hair loss, edema, and the weight variation in grams. The offsprings of these treated female rabbits were used for the research purposes. They were sacrificed after reaching the age of 3 months to obtain their upper and lower jaws. The procedure was done, taking immense care, not to damage the

teeth. These jaws were checked regarding the eruption, status and alignment of the teeth.

Dental formula of the permanent human dentition is documented as:

I-2/2:C-1/1:Pm-2/2:M -3/3 ( $\times 2$ = 32 total teeth). ${ }^{15}$

Unlike human dentition, the dental formula of the rabbit teeth is:

I-2/1:C-0/0:Pm-3/2:M -3/3 ( $\times 2=28$ total teeth). ${ }^{16,17}$

Rabbit's teeth, just like the human dentition, are also identified with their particular code numbers ${ }^{18}$ as follows:

101-Right maxillary central incisor

102-Right maxillary lateral incisor

106-Right maxillary first premolar

107-Right maxillary second premolar

108-Right maxillary third premolar

109-Right maxillary first molar

110-Right maxillary second molar

111-Right maxillary third molar

301-Left mandibular incisor

307-L eft mandibular first premolar

308-L eft mandibular second premolar

309-L eft mandibular first molar

310-L eft mandibular second molar

311-L eft mandibular third molar

Different dental instruments were used for extracting the teeth from the jaws, e.g. tw eezers, artery forceps, alveolar bone cutter, interdental scal er and contra-angle hand piece fixed with the diamond point burs (round/fissure).

Extracted teeth were then washed by deionized or distilled water in a dappen dish and preserved in 10\% formalin in the bottles, which were labelled with their individual code numbers for each sample of the tooth.

\section{IMAGES OF TEETH STUDIED BY SEM-EDX}

Effect of the drug on the extracted teeth was studied by the images of ultrastructure of enamel taken by scanning electron microscope and energy dispersive $X$-ray spectroscopy (SEM EDX). A nalysis using scanning electron microscopy (SEM) and energy-dispersive $X$-ray microanalysis (EDX), has been done 
by several researchers. ${ }^{19-23}$ Surveying the prior studies, the scanning electron microscope was found to be well suited for the analysis of the developmental defects of enamel surface. It is a type of electron microscope that images the sample surface by scanning it with a high-energy beam of el ectrons in a raster scan pattern. TheSEM can produce very high-resolution images of a sample surface, revealing the details about 1 to $5 \mathrm{~nm}$ in size. ${ }^{24}$ Each sample was coated with gold up to $300^{\circ} \mathrm{A}$ using Quick A uto Coater, model no. JFC-1500 Jeol. A fter the completion of the gold coating, the samples were then ready for analysis. Scanning electron microscope (6380A J eol) with EDS detector (Ex-54175 J mu J eol) was used for the analysis. A round four samples could be loaded at a time in the SEM chamber and mounted rigidly on the specimen holder called specimen stub. All the parameters were kept uniformly for analyzing each sample, i.e. accelerating voltage $15.0 \mathrm{kV}$, magnification 10,000 , standardless quantification technique with ZA F correction ${ }^{25}$ SSM Dead time about 20 to $45 \% .{ }^{26} \mathrm{All}$ the images were taken at the same magnification and under the same conditions.

\section{RESULTS}

Images of 12 samples with their code nos. 101, 106, 109, 201, 206, 209, 301, 307, 309, 401, 407 and 409 from the individual subject of both the groups were taken by SEM-EDX and included in the study.

The total number of teeth imaged were, $2 \times 7 \times 12=168$ samples. The selection provided the analysis for each of the three types of teeth (incisors, first premolars and first molars) in the maxillary as well as in the mandibular arch. Furthermore, both left and the right sides of the oral cavity were represented through these images.

Selective images depict features in a very clear manner. A n overall assessment of these images reflected quite an uneven or undulating surface. The distorted anatomical landmarks, i.e. abraded ridges and deep eroded grooves, were noted on all the surfaces of molar and incisor teeth (Figs 1 and 2) of treated specimens. V ery large variations were observed within the samples from the control or the treatment groups. It was evident in this study that the drug had caused erosions of incisors and the first molars (see Figs 1 and 2), which was more marked than their effect on the premolars (Fig. 3).

Three images (incisor, first premolar and first molar) from both the groups are included in the article, as all 168 images could not be represented here.

\section{DISCUSSION}

The developmental defects of teeth, expected to be caused by the use of lithium during pregnancy, were thoroughly searched and studied in the published literature. The effect of in utero exposure of this drug on the developing teeth of neonates has not been reported before. Some studies have shown the effect on bone, e.g. lithium treatment of humans and animals has been associated with adverse effects on bone and mineral

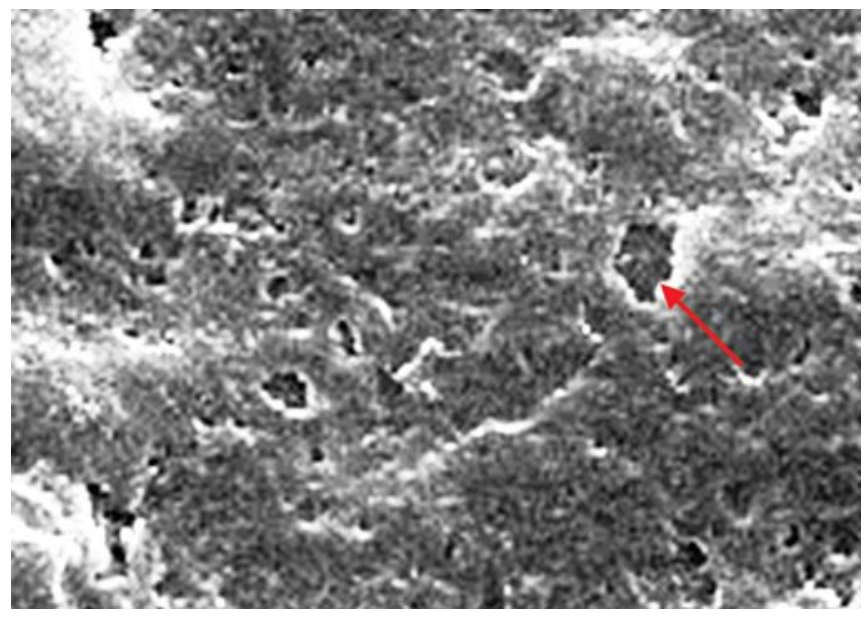

Fig. 1: Extensively demineralized enamel rods were evident on the surface of right maxillary central incisor (Experimental group) (Y6-2, Code no. 101)

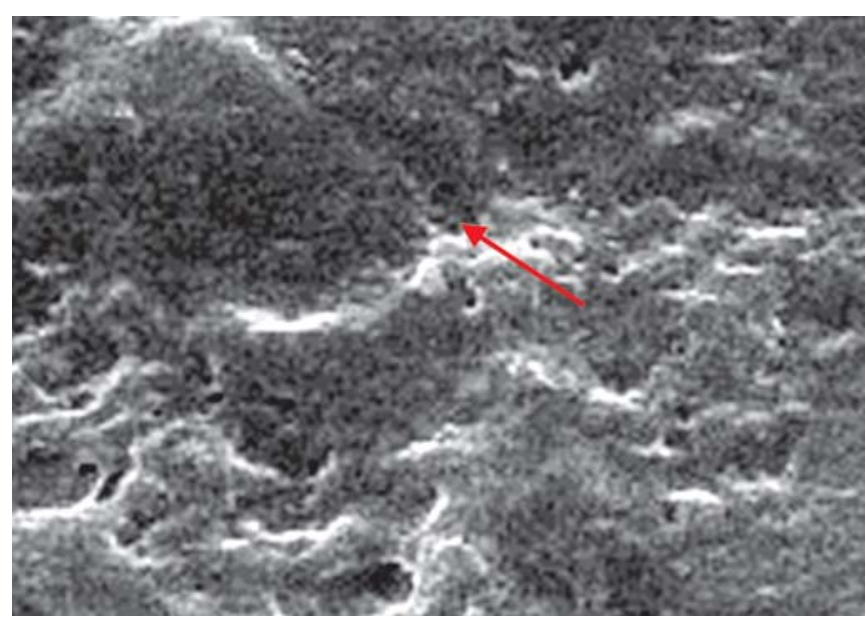

Fig. 2: Left mandibular first molar (Experimental group) appeared with several micropores indicating open enamel prisms and demineralization (Y7-2, Code no. 309)

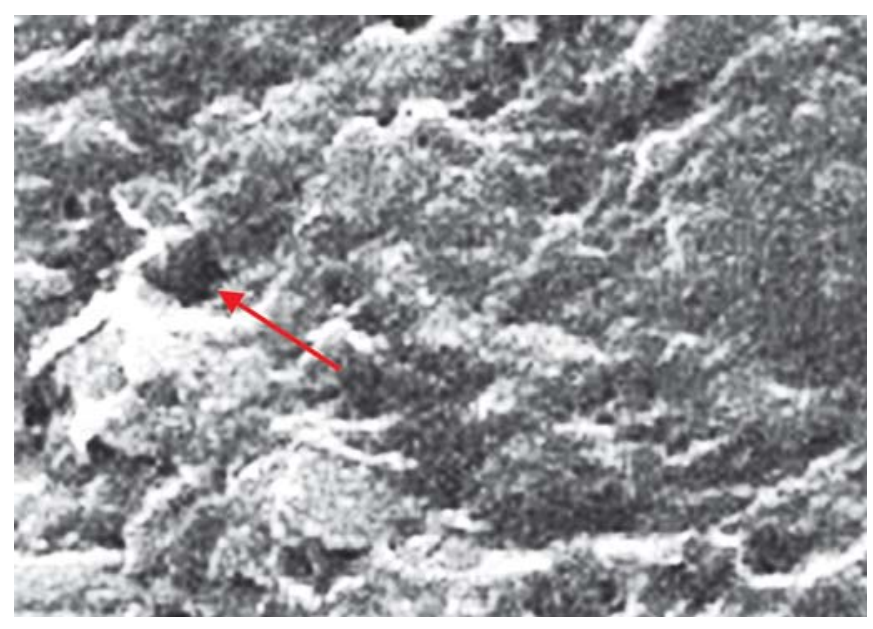

Fig. 3: Extensive abrasion and demineralization was visible on the right maxillary first premolar (Experimental group) (Y2-5, Code no. 106)

metabolizm. ${ }^{27}$ The lithium treatment resulted in a decrease in bone mineral content occurring within the first 6 months of lithium treatment. ${ }^{28}$ Lithium-associated fetal nephrotoxicity was also reported. ${ }^{29}$ 


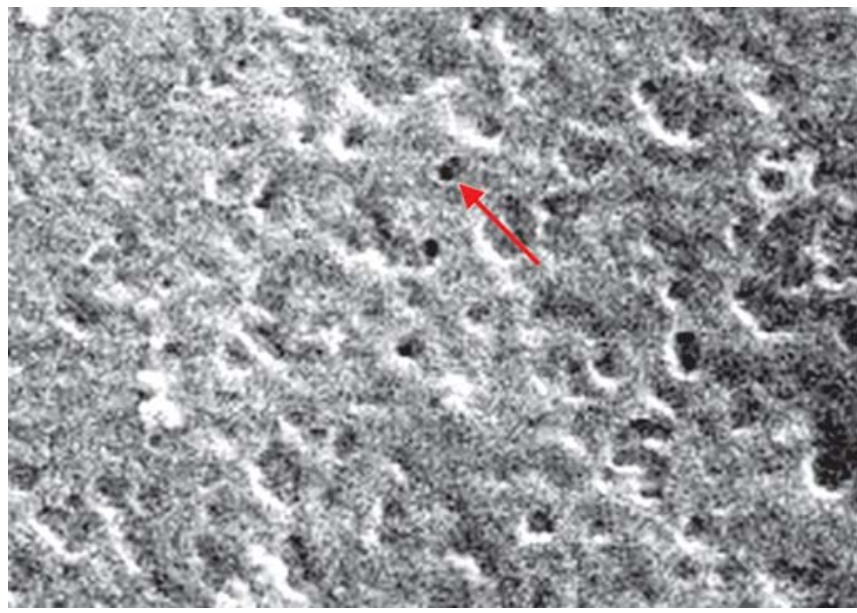

Fig. 4: SEM image of the crown surface of right maxillary central incisor appeared with micropores (Control group) (N-1, Code no. 101)

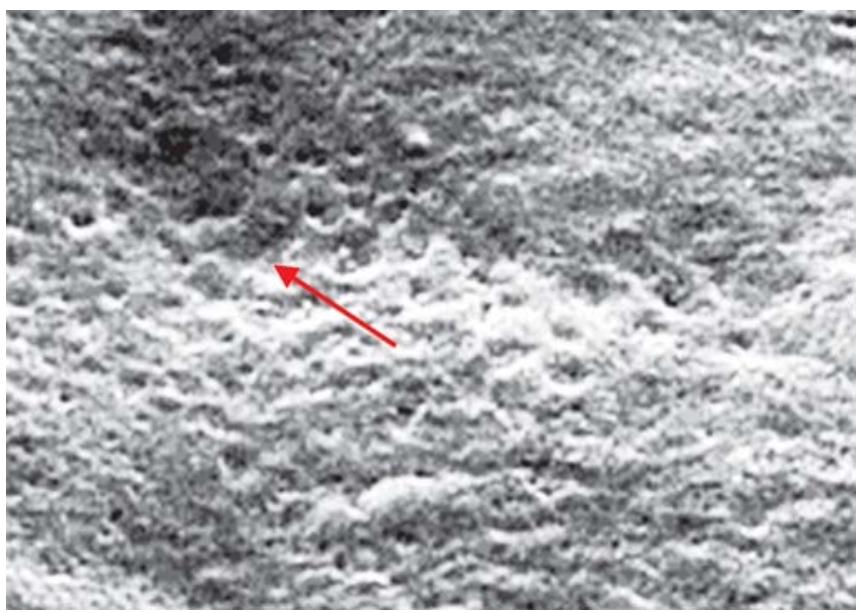

Fig. 5: Very shallow pits appeared on the surface of the left mandibular first premolar (Control group) (N-2, Code no. 307)

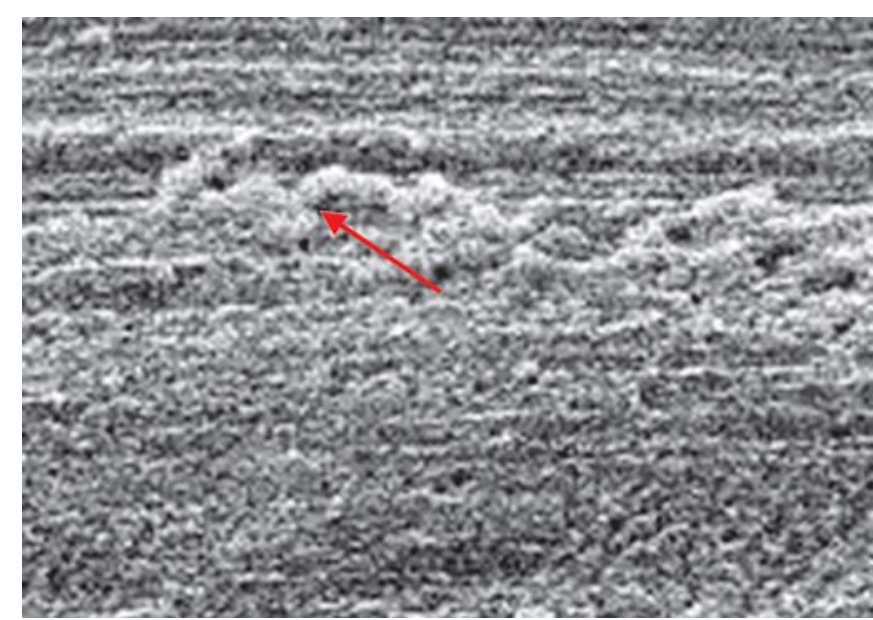

Fig. 6: Maxillary right first molar showed a small area of abrasion but no demineralization (Control group) (N-4, Code no. 109)

In the present study, images of the teeth obtained from the SEM examination in treated and the control groups were studied. A large variety in textures was apparent on the surface structure of enamel. The distorted anatomical landmarks, i.e. abraded ridges and deep eroded grooves, were noted. Exposed enamel rods were also observed on the tooth surface of the experimental group, showing the demineralization of the enamel surface (see Figs 1 to 3), as compared to the abraded tooth surfaces of the central group (Figs 4 to 6 ), which is formed due to masticatory process.

A ccording to the reports of the prior studies, SEM images of enamel surface in higher magnification reveal ed lacunae with various patterns of resorption, in addition showed resorbing enamel prisms in longitudinal and other orientations. ${ }^{30}$ Extent and evolution of the enamel alterations were limited to the outer enamel. ${ }^{19}$ The hypomineralized enamel showed fewer distinct features compared with the normal enamel. ${ }^{21}$ Enamel from primary teeth of preterm children was found to have a high frequency of mineral ization disturbances. ${ }^{23} \mathrm{~A}$ Ithough there are some evidences of the enamel al terations, studied by SEM , but none of them was studied in response to any drug treatment. The teratogenic risk of lithium on the developing teeth of the fetus while the mothers were treated by this drug during pregnancy have not been studied/reported in prior studies. Whereas, the results derived from the present study were in response to the in utero exposure of lithium on the devel oping teeth. However, it was difficult to determine either the type of the tooth or its location in the maxillary or mandibular arch, merely by the study of their SEM images.

A single intrauterine exposure to a drug can affect the fetal structures undergoing rapid development at the time of exposure. ${ }^{14} \mathrm{H}$ ypothyroidism may also develop in lithium treated patients and could effect in childhood, e.g. the teeth may fail to erupt, al though tooth formation may not be impaired. ${ }^{31}$

The result of another report was particularly noted that the drug has resulted in a decrease in bone mineral content occurring within the first 6 months of lithium treatment. ${ }^{28}$ It could thus be hypothesized that any drug influencing the minerals of bone could also effect the mineralization of teeth. The hypothesis was based upon a strong reason, and that was the similarity of the inorganic component in both the tissues, and an important component called 'hydroxyapatite'. Therefore having the same chemical composition and in light of the prior reports, ${ }^{4,6,14}$.the possibilities of adverse effect were anticipated on the dental tissues also.

In the present study, variations in the images were observed within the samples from the control or the treatment groups. These variations overshadow any aggregate differences between the groups. It is quite evident that some of the teeth in the dental arch were more affected during the devel opmental stages. The results of this study reveal ed that incisors and the molars were the most affected teeth. These findings corresponded with the results obtained from the previous studies. ${ }^{7,8}$ L unardelli and Peres (2005) have reported that for the enamel hypoplasia of human deciduous dentition, the most affected teeth were the canines. ${ }^{16,17} \mathrm{H}$ owever, the results of $L$ unardelli and Peres, could not be compared with the present study because rabbits have been used as an animal model and they do not have canines. ${ }^{15}$ The prevalence of enamel opacity in primary dentition was 
SEM-EDX Analysis for Surface Aberrations of Neonate's Teeth Influenced by the use of Lithium in Pregnancy

reported ${ }^{32}$ to be mostly affecting the upper and lower second primary molars. The maxillary and mandibular primary incisors and the maxillary first primary molars were affected by enamel hypoplasia. The enamel defects in the first permanent molars among children were high. ${ }^{8}$ It was al so reported ${ }^{7}$ that the most affected teeth were the second molars, followed by the first molars.

The above findings $s^{7,8,32}$ correspond with the present study regarding the teeth influenced during developmental stages. In the present study, the most affected teeth were the first molars (Fig. 3). However, it is important to note that the reports of the prior studies were not in response to any drug treatment, whereas the present study was done to evaluate the effect of in utero exposure of lithium resulting into developmental defects of teeth, i.e. the drug had caused erosions of incisors and first molars. Such type of study has not been reported before.

\section{CONCLUSION}

Facial esthetics are associated to the dentition and facial tissues. The dentofacial abnormality may cause psychological disturbances in children. This study was initiated to assess the alterations in ultrastructure of enamel surface in the teeth of newborn babies of the mothers, who have been using lithium for a long time during pregnancy.

The gross morphological appearances of enamel by the scanning electron microscope (SEM) provided the qualitative understanding. It was concluded from the obtained results that the incisors and the molars were subjective to in utero exposure of lithium and were esthetically and functionally compromised teeth. H owever, malformations caused by any drug are important and preventable, for which an efficacious preventive action must therefore be taken. The drug should therefore al ways be used by doctor's prescription only, especially during pregnancy, avoiding in every way the possibility of self-medication, which could ultimately result in teratogenic effect on the dentition of the newborns. Furthermore, to achieve the esthetic and functional goals, a problem oriented logical treatment plan is especially useful.

\section{REFERENCES}

1. Potter WZ, Hollister LE. A ntipsychotic agents and lithium. In: Katzung BG (Ed). Basic and clinical Pharmacology (10th ed). The M C Graw-Hill companies: USA 2007;457-74.

2. Seymour RA, Rudralingham M. Oral and dental adverse drug reactions. Periodontology 2008;46(1):9-26.

3. Baldessarini RJ, Tarazi FJ. Drugs and treatment of psychiatric disorders. In: Hardman J G, L imbird LE, Gillman A G (Eds). The pharmacological basis of therapeutics (10th ed). The M CGrawHill Companies: USA 2001;485-520.

4. B hattacharya SK, Sen P, Ray A. Geriatric, paediatric and perinatal pharmacology. In: Das PK (Ed). Pharmacology (2nd ed). 2003;501-23.

5. Foley M R. Drug use during pregnancy. Women's health issues. The M erck M anuals 2007.

6. A bdollahi M, Rahimi R, Radfar M. Current opinion on druginduced oral reactions: A comprehensive review. Journal of Contemporary Dental Practice 2008;9(3):1-15.
7. Lunardelli SE, Peres MA. Prevalence and distribution of developmental enamel defects in the primary dentition of preschool children. Brazilian Oral Reserch 2005;19(2):144-49.

8. A rrow P. Prevalence of developmental enamel defects of the first permanent molars among school children in Western A ustralia. A ustralian D ental J ournal 2008;53(3):250-59.

9. Thomas SV, Nair RR, J ose M, et al. Risk of major congenital malformations in the offsprings of women with epilepsy is not related to family history. E pilepsy Research 2009;83:52-57.

10. Rubin P. Drug treatment during pregnancy. BMJ 1998; 317:1503-06.

11. Rubin PC. Prescribing in pregnancy. Medical Practice BMJ. 1986;293(6559):1415-17.

12. Karen $\mathrm{E}$ Lange, Lithium Rush. $\mathrm{Nal}$ Geog M agazine available at: http://blogs.ngm.com/blog_central/2009/08//ithiumrush.html. A ccessed, A ug 2009.

13. Neurolith ${ }^{\circledR}$ SR (Reg. no. 015620). One tablet contains lithium carbonate BP $400 \mathrm{mg}$. M anufactured by A damjee Pharmaceuticals (Pvt.) L td. K arachi, Pakistan.

14. Koren G. Special aspects of perinatal and pediatric pharmacology. In: K atzung BG (Ed). Basic and clinical Pharmacology (10th ed). The M CG raw-Hill companies. USA 2007; 971-82.

15. Fuller J L. Introduction and nomenclature. In: Fuller J L, D enehy GE (Eds). Concise dental anatomy and tooth morphology (3rd ed) 2006;2-20.

16. M eredith A. Rabbit dentistry. EJCAP 2007;17(1):55-62.

17. Weisbroth $\mathrm{SH}$, Ehrman L. M alocclusion in rabbit: A model for the study of the development. Pathology and inheritance of malocclusion. J ournal of Heredity 1967;58:245-46.

18. Johnston N. Tooth numbering in other species (rabbit). The modified tradian system. Based on image supplied by David Crossl ey. V eterinary D entistry. Basics 2002; eM edia U nit RV C.

19. Chardi H, A cevedo AC, Risnes S. SEM study of the development of rat incisor enamel hypoplasia under hypocalcemia induced by thyro-parathyroidectomy. Connective Tissue Research 1998; 39(1-3):157-64.

20. M ishima H, K ozawaY. SEM and EDS analysis of cal cospherites in human teeth. Europeon Journal of Oral Sciences 1998;106 (Suppl 1):392-96.

21. Jalevik B, Dietz W, Noren JG. Scanning electron micrograph analysis of hypomineralized enamel in permanent first molars. International J ournal of Paediatric Dentistry 2005;15:233-40.

22. A rnold WH, Naumova KI, Naumova EA, et al. Comparative qual itative and quantitative assessment of biomineralization of tooth development in man and zebra fish (Danio rerio). A nat Rec (Hoboken) 2008;291(5):571-76.

23. Rythen M, Noren J G, Sabel N, et al. M orphological aspects of dental hard tissues in primary teeth from preterm infants. International J ournal of Paediatric Dentistry 2008;18:397-406.

24. Wikipedia, the free encyclopedia. Scanning electron microscope. A vailable at: <http://SEM - encyclopedia.mht>. A ccessed, Sep 2009.

25. UCLEMA. Fundamentals for electron microprobe analysis (EM PA ). A vailable at: <http://www.geo.ucalgary.ca/U CLEM A/ EM PA 1.html>. A ccessed, Sep 2009.

26. Egerton RF. A nalytical electron microscopy. In: Egerton RF (Ed). Physical princples of electron microscopy. A $n$ Introduction to TEM , SEM , AEM 2005;164-65.

27. Baran DT, Burks JK, Richardson CA, et al. Effect of lithium on parathyroid hormone-induced calcium release from bone rudiments. Calcified tissue international 1979;27(1):127-28. 
28. Plenge $P$, Rafaelsen 0 J. L ithium effects on cal cium, magnesium and phosphate in man: Effects on bal ance, bone mineral content, faecal and urinary excretion. Acta Psychiatrica Scandinavica 1982;66(5):361-73.

29. Newport DJ, V iguera AC, B each AJ, et al. Lithium placental passage and obstetrical outcome: Implications for clinical management during late pregnancy. A merican Journal of Psychiatry 2005;162:2162-70.

30. A rana-Chavez $V E$, A ndia-M erlin RY. Scanning electron microscopy examination of resorbing enamel surfaces in unexfoliated primary molar teeth. ASDC Journal of Dentistry for Children 1998;65(3):182-85.

31. Neville BW, Damm DD, A llen CM, et al. O ral manifestations of systemic diseases. In: Neville BW, Damm DD, Allen CM, and Bouquot JE (Eds). Oral and M axillofacial Pathology (2nd ed). Saunders: Philadel phia, Pennsylvania 2007;705-40.

32. Zheng $S, D$ eng $H, B$ ao $Y$. The study on the clinical manifestation of developmental enamel defects in primary dentition. Hua Xi Kou Qiang Y i Xue Za Zhi 2003;21(3):200-1, 204. 